\title{
Parameterization, Verification, and Validation of a Physiologically Complex Age-structured Rice Simulation Model
}

\author{
G. W. Wu \& L. T. Wilson* \\ Department of Entomology, Texas A\&M University, College Station, TX 77843, USA
}

(Received 15 October 1996; revised version received 6 October 1997; accepted 13October 1997)

\author{
ABSTRACT
}

\begin{abstract}
A model of rice (Oryza sativa L.) growth and development is presented which accurately simulates the seasonal numbers and mass of roots, culms, leaf sheaths, leaf blades, panicle vegetative components, and grainsfor the main tillers and subtillers. The physiological detail imbedded within the model departed to the greatest degree from previously published rice simulation models in its tiller cohort and plant part age structure, and its metabolite partitioning structure. Possibly the greatest distinction between RICEPSM and previously developed rice models is the inclusion of a statistically rigorous model parameterization, verijication. and validation process. The verijicationvalidation approach used in this paper has the advantage of enabling the individual and collective fit of multiple response variables. The verified model explained $88 \%$ of the variability across 13 data types, with 88 and $93 \%$ of the variability explained for main tiller and subtiller grain yield, respectively. When validated against a second year of data, $87 \%$ of the variability across the 13 data types, and 92 and 95\% of main tiller and subtiller grain yield, respectively, was explained. The paper contrasts the verification and validation approach presented in this paper with that used in other simulation-basedpape:s. (C) 1997 Elsevier Science Ltd. All rights reserved
\end{abstract}

\section{INTRODUCTION}

A number of rice simulation models have been developed (van Keulen, 1978; Angus and Zandstra, 1980; McMennamy and O'Toole, 1983; Huang and Wang, 1986; Ritchie et al., 1987; Costello et al., 1988; Zhang and Chen, 1990; Graf et al., 1990b; Miller et al., 1993; Salam et al., 1994; Singh and Padilla,

*Towhom correspondence should be addressed. Fax: (409) 845-6305. 
1995). These models represent a range of approaches to analyzing the response of rice to physical, agronomic, and biotic factors. Perhaps the most detailed rice model, RICEMOD was developed by McMennamy and O'Toole (1983). The objective of this model was to describe the complex biochemical and biophysical systems interacting in a rice crop. In contrast to RICEMOD and the other models listed above, Graf et $a l$. (1990b) developed a rice model that uses a demographic and metabolic pool approach which is based on earlier models developed by Gutierrez and co-workers (Gutierrez and Wang, 1976). Although this model captures less physiological detail, it contains an age structure, a characteristic which facilitates evaluating the impact of physical and abiotic stresses on rice growth, development, and yield, and linking plant models with herbivore, pathogen, nematode, and weed population models.

The value of a simulation model is in part dependent on its ability to realistically mimic targeted response variables. Initially parameterized models frequently fail to accurately fit data from which the models were at least in part developed. To correct this situation, some parameters or functions are adjusted within biologically reasonable limits, and the new model output is again compared with the dependent data. This process is called model verification. In contrast, validation is the comparison of output from a verified model with independent data, followed by statistical analyses that test the degree of fit. Without a statistically rigorous validation, a verified model represents little more than a sophisticated curve-fitting and does not enable a statement of certainty as to its ability to capture a crop's response to major physical, agronomic, and biotic variables.

The goal of this paper is to use an analytical approach to quantify the response of rice to major physical variables. The approach presented comprises development of a model which combines the features of a physiologically complex model with an age-structured model. We parameterize the model, herein referred to as RICEPSM (RICE Population Simulation Model), using data obtained from the literature and field experiments. The ability of RICEPSM to capture the response of rice to major physical (i.e. daily maximum and minimum temperatures, and solar radiation) and agronomic variables (i.e. planting date, amount and timing of nitrogen applications, first day of permanent flooding, and plant density) is then tested using a rigorous statistically based parameterization-verification-validationprocedure.

\section{MATERIALS AND METHODS}

\section{Data sources for model parameterization}

Table 1 summarizes the data sources used to parameterize RICEPSM. To estimate parameters that were not available through the literature, and to 
TABLE 1

Data Sources for Parameterizing the Physiologically-Based Rice Population Model

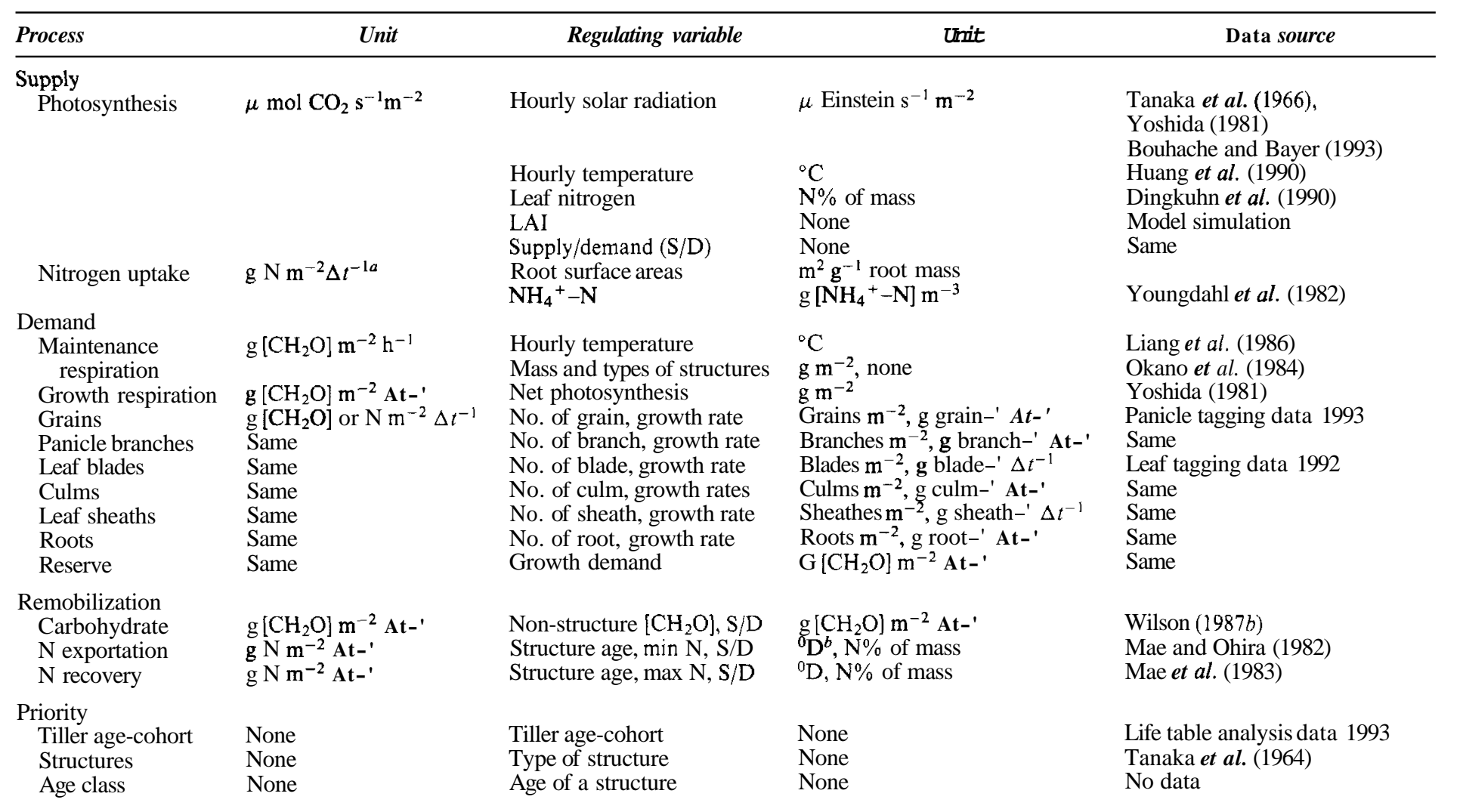


Table 1-contd

\begin{tabular}{|c|c|c|c|c|}
\hline Process & Unit & Regulating variable & Unit & Data source \\
\hline $\begin{array}{c}\text { Allocation } \\
\text { Grains }\end{array}$ & $\begin{array}{l}\mathrm{g}\left[\mathrm{CH}_{2} \mathrm{O}\right] \text { or } \\
\mathrm{N} \mathrm{m}^{-2} \Delta t^{-1}\end{array}$ & $\mathrm{~S}^{c}, \mathrm{D}_{\mathrm{i}}^{d}, \mathrm{P}_{\mathrm{i}}^{e}$ & $\begin{array}{l}\mathrm{g} \mathrm{m}^{-2} \Delta t^{-1} \\
\mathrm{~g} \mathrm{~m}^{-2} A t-{ }^{\prime} \text {, none }\end{array}$ & $\begin{array}{l}\text { Same sources as cited in Supply, } \\
\text { Demand and Priority sections }\end{array}$ \\
\hline Panicle branches & Same & $S, D_{i}, P_{i}$ & Same & Same \\
\hline Leaf blades & Same & $\mathrm{S}, \mathrm{D}_{\mathrm{i}}, \mathrm{P}_{\mathrm{j}}$ & Same & Same \\
\hline Clums & Same & $\mathrm{S}, \mathrm{D}_{\mathrm{i}}, \mathrm{P}_{\mathrm{i}}$ & Same & Same \\
\hline Leaf sheaths & Same & $S, D_{i}, P_{i}$ & Same & Same \\
\hline Roots & Same & $\mathrm{S}, \mathrm{D}_{\mathrm{i}}, \mathrm{P}_{\mathrm{i}}$ & Same & Same \\
\hline Reserve & Same & $\mathrm{S}, \mathrm{D}_{\mathrm{i}}, \mathrm{P}_{\mathrm{i}}$ & Same & Same \\
\hline \multicolumn{5}{|l|}{ Birth } \\
\hline Tiller & Tillers $\mathrm{m}^{-2}, \boldsymbol{A t} \mathbf{-}^{\prime}$ & $\mathrm{S} / \mathrm{D}, \mathrm{N}^{f}$ & None, $\mathrm{N} \%$ of mass & Life table analysis data 1993 \\
\hline Grains & Grains tiller-', $\Delta t^{-1}$ & $\mathrm{~S} / \mathrm{D}$, Mass at $\mathrm{PI} g$ & None, g plant-' & Destructive sampling 1992 \\
\hline Panicle branches & Branches $\mathrm{m}^{-2}$ At- & Nodes, $\mathbf{N}$ & Nodes maintiller-' & Life table analysis data 1993 \\
\hline Leaf blades & Leaf baldes $\mathrm{m}^{-2} \Delta t^{-1}$ & $\mathrm{~S} / \mathrm{D}, \mathrm{N}$ & None, $\mathrm{N} \%$ of mass & Same \\
\hline Culms & Culms $\mathrm{m}^{-2}$ At-' & $\mathrm{S} / \mathrm{D}, \mathrm{N}$ & Same & Same \\
\hline Leaf sheaths & Leaf sheaths $\mathrm{m}^{-2} A t-^{\prime}$ & $\mathrm{S} / \mathrm{D}, \mathrm{N}$ & Same & Same \\
\hline Roots & Roots $\mathrm{m}^{-2} \Delta t^{-1}$ & $\mathrm{~S} / \mathrm{D}, \mathrm{N}$ & Same & Same \\
\hline \multicolumn{5}{|l|}{ Growth and aging } \\
\hline Grains & $\mathrm{g} \mathrm{m}^{-2}$ & Allocation, $\varepsilon^{h}$ & $\mathrm{~g} \mathrm{~m}^{-2}$, none & $\begin{array}{l}\text { Leaf tagging data } 1992 \\
\text { Life table analysis data } 1993\end{array}$ \\
\hline Panicle branches & Same & Same & Same & Same \\
\hline Leaf blades & Same & Same & Same & Same \\
\hline Culms & Same & Same & Same & Same \\
\hline Leaf sheaths & Same & Same & Same & Same \\
\hline Roots & Same & Same & Same & Same \\
\hline
\end{tabular}


Table 1—contd

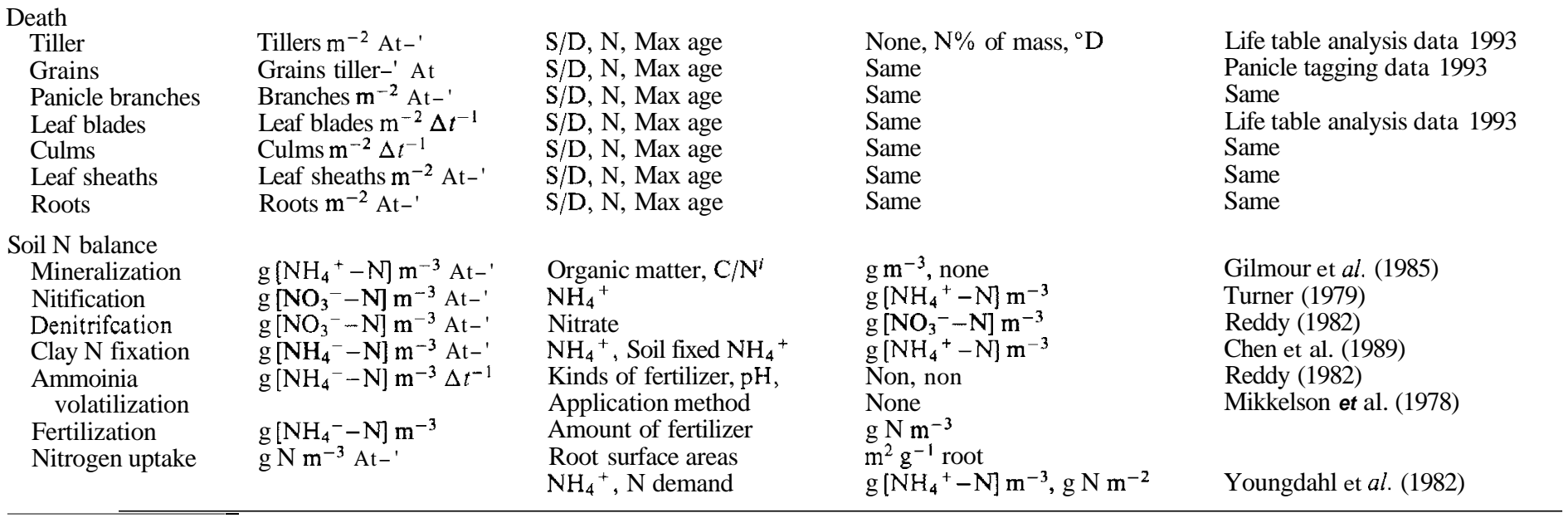

${ }^{a} \Delta t=$ simulation time step $\left(40\right.$ degree-days $\left.>10^{\circ} \mathrm{C}\right)$.

${ }^{h} \mathrm{D}=$ cummulative degree-days greater than $10^{\circ} \mathrm{C}$ from the structure initiation.

${ }^{\mathrm{C}} \mathrm{S}=$ supply

${ }^{2} \mathrm{D}_{\mathrm{i}}=$ demand of structure $\mathrm{i}$.

${ }^{e} \mathrm{P}_{\mathrm{i}}=$ priority of structure $\mathrm{i}$.

$f_{\mathrm{N}}=$ nitrogen content of a plant.

$g \mathrm{PI}=$ panicle initiation.

$h_{\mathcal{E}}=$ the proportion of mass or numbers moving into the next age-class each simulation step.

${ }^{\circ} \mathrm{C} / \mathrm{N}=$ carbohydrate/nitrogen ratio in organic matter. 
verify and validate RICEPSM, field experiments were conducted in 1992 and 1993 at the Texas A\&M University System Agricultural Research and Extension Center at Beaumont, Texas. The 1992 and 1993 field experiments both used a completely randomized plot design. In 1992, the rice was drillseeded on May 8 at a rate of $90 \mathrm{~kg} \mathrm{ha}^{-1}$ with a 0.18 meter-row spacing. When rice seedlings reached the third to fourth leaf stage, plants were hand thinned to a uniform density of about 20 plants per meter-row. Nitrogen fertilizer (ammonium sulfate) was applied at a rate of $90 \mathrm{~kg} \mathrm{~N} \mathrm{ha}^{-1}$ before planting, $45 \mathrm{~kg} \mathrm{~N} \mathrm{ha}^{-1}$ before permanent flooding, and $45 \mathrm{~kg} \mathrm{~N} \mathrm{ha}^{-1}$ at panicle differentiation. The herbicide Propanil $\left(3.92 \mathrm{~kg} \mathrm{Al} \mathrm{ha}^{-1}\right)$ and the insecticide Furadan $\left(0.56 \mathrm{~kg} \mathrm{Al} \mathrm{ha}^{-1}\right)$ were used to suppress weeds and rice water weevil on June 3 and June 25, respectively. In 1993, the rice was drillseeded on March 27 at a rate of $180 \mathrm{~kg} \mathrm{ha}^{-1}$ and hand thinned to a uniform density of about 20 plants per meter-row as 1992 . Propanil $\left(3.92 \mathrm{~kg} \mathrm{Al} \mathrm{ha}^{-1}\right)$ and Furadan $\left(0.56 \mathrm{~kg} \mathrm{Al} \mathrm{ha}^{-1}\right)$ were used to suppress weeds and rice water weevil on May 18 and May 29, respectively.

Twelve and six plots each were reserved for destructive sampling in 1992 and 1993, respectively. Each plot had six rows by $6 \mathrm{~m}$, and was divided into six subplots. Rice grown in the center four rows and center $0.5 \mathrm{~m}$ of a subplot was destructively sampled in 1992, while samples were taken from the center four rows and $0.33 \mathrm{~m}$ of a subplot in 1993. During both years, sampling frequency was twice a week prior to panicle differentiation and once a week thereafter. Rice plants were removed with the soil to a depth of $40 \mathrm{~cm}$ to collect all roots. Samples were washed and divided into four groups: (1) main tillers arising from seeds, (2) first two subtillers of a main tiller, (3) third and fourth subtillers of a main tiller, and (4) the remaining subtillers. Tillers in each group were separated into five structural categories: root, stem (culm and leaf sheath), leaf blade, panicle vegetative component (branches and rachis), and grain. Measurements for each tiller group included: (1) number of tillers, (2) nodes per tiller, (3) leaf area (measured using a model CI-251 leaf area meter, CID, Inc.), and (4) number of filled and unfilled grains per panicle. All samples were oven-dried at $75^{\circ} \mathrm{C}$ to a constant weight, and each structure category for each tiller group was weighed.

In addition, 20 leaves from each position (leaves arising from the same node of the culm) for each group were subsampled once a month, and the length, width, and area of each leaf was measured. Three to four hundred newly emerging leaves $(<3 \mathrm{~cm}$ long) were tagged on each of three dates corresponding to early tillering, panicle differentiation, and flag leaf emergence. Two to three times a week, 20 tagged leaves were randomly harvested from each tagging. Each leaf was measured for leaf area, oven-dried, and weighed. These data were used to derive an average leaf growth curve for each of the three leaf cohorts. About 300 plants were tagged upon emergence 
of each panicle from its flag leaf sheath (the visible part of a panicle $<10 \mathrm{~cm}$ long). Two to three times a week, 20 tagged panicles were collected. The number of unfilled (includes partially filled) and filled spikelets (grain) were counted, oven-dried, and weighed. These data provided estimates of the number of spikelets per panicle, grain size, growth rate, and proportion of filled spikelets. The field experiments are described in detail by Wu (1996).

\section{Model structure}

Table 2 summarizes the major physiological processes and functions within RICEPSM. RICEPSM is comprised of subpopulations of tillers of different ages, with each tiller consisting of panicles, stems (culm plus leaf sheath), leaves, and roots, each characterized by numbers, biomass, and age structure. Tillers are categorized into 12 age-cohorts based on the time at which they are initiated. The mass for each structure type within each tiller agecohort for each age class is comprised of structural and non-structural carbohydrate, and nitrogen.

Initiation, growth, and development of each structure (leaf, root, sheath, culm, grain) is based on a physiological or degree-day time scale which was calculated using the double-sine approximation method (Allen, 1976). A $10^{\circ} \mathrm{C}$ lower temperature threshold for rice growth and development was obtained from the literature (Yoshida, 1981; Liang, 1983). For each time step, plant carbohydrate and nitrogen balances are used in simulating aging, and tiller and structure specific initiation and senescence rates. The time step for the population processes is $\mathbf{4 0}$ degree-days ("D) $>10^{\circ} \mathrm{C}$, except for photosynthesis and respiration which are simulated hourly. A $40^{\circ} \mathrm{D}$ time step coincides with a 2 to $\mathbf{3}$ day time interval during the summer months. The time step is sufficiently small to match the sampling interval for the most detailed aspects of the field experiments.

A distributed-maturation algorithm (Plant and Wilson, 1986) is used to simulate the dynamics of organ initiation, growth, aging, and senescence. This equation integrates the intrinsic variability in structural growth and aging, estimated from field data, based on the McKendrick equation (McKendrick, 1926; Von Foerster, 1959). Each plant structure type has $l_{k}$ age classes $\left(l_{k}\right.$ is equal to the ratio of the kth structure's developmental duration divided by the length of a time step) and $l_{k}$ differential equations specifying the change in mass or numbers each time step.

\section{Light interception and photosynthesis}

Light interception is simulated using a layered canopy submodel (Wilson et $a l ., 1987 a, b)$. The amount of incident solar radiation intercepted by each layer of leaves with common age depends on its leaf area index $\left(L A l_{j}\right)$ and is 
TABLE 2

A Summary of Major Equations used in RICEPSM

\begin{tabular}{|c|c|c|}
\hline Process & Equation & Descriptions \\
\hline Light interception & $P A R_{j, i}=P A R_{0, i}\left(e^{-a L A I_{H-1}}-e^{-a L A I_{i}}\right)$ & $\begin{array}{l}P A R_{j, i}: \text { PAR intercepted by thejth leaf layer at } \\
\text { the ith hour of a day; } P A R_{0, i}: \text { the light intensity } \\
\text { above the leaf canopy at the ith hour of a day; } \\
\text { a: the light extinction coefficient }\end{array}$ \\
\hline Photosynthesis rate & $P_{g, j, i}=31 \cdot 5657\left(1-e^{-0009296 P A R_{j, l}}\right)$ & $\begin{array}{l}P_{g, j, i}: \text { the potential gross photosynthesis rate } \\
\left(\mu \mathrm{mol} \mathrm{CO}_{2} \mathrm{~m}^{-2} \text { leaf area } \mathrm{s}^{-1}\right) \text { minus photo- } \\
\text { respiration, for thejth leaf layer, at the ith hour } \\
\text { of a day, at the optimum temperature and leaf } \\
\text { nitrogen content. } P A R_{j, l}\left(\mu \text { Einstein's } \mathrm{m}^{-2} \mathrm{~s}^{-1}\right) \text { is } \\
\text { the intensity of light intercepted by the jth leaf } \\
\text { layer at the ith hour of a day }\end{array}$ \\
\hline Temperature effect & $C_{T}=\left\{\begin{array}{cc}-0.434+0 \cdot 103^{\circ} \mathrm{C}-0.00184^{\circ} \mathrm{C}^{2} & 5<{ }^{\circ} \mathrm{C}<51 \\
0 & \text { Otherwise }\end{array}\right.$ & ${ }^{\circ} \mathrm{C}$ : mean temperature \\
\hline Nitrogen effect & $C_{N}=\left\{\begin{array}{cc}-0.197+0.521 N_{l}-0.0566 N_{l}^{2} & 0.4<N_{l}<8.8 \\
0 & \text { Otherwise }\end{array}\right.$ & $N_{l}$ : leaf nitrogen content \\
\hline Potential photosynthesis & $P_{g, i}=C_{T}^{*} C_{N}{ }^{*} \sum_{j=1}^{I}\left(P_{g, j, i}^{*} L A I_{j}\right)^{*} 3600$ & $l$ : the number of leaf layers; LAZ: leaf area index \\
\hline Respiration & $\begin{aligned} R_{m}= & \left(r_{r}{ }^{*} m_{r}+r_{s}{ }^{*} m_{s}+r_{c}{ }^{*} m_{c}+r_{l}{ }^{*} m_{l}+r_{p}{ }^{*} m_{p}+r_{g}\right. \\
& \left.{ }^{*} m_{g}\right)^{*} Q_{10}^{(T-20) / 10}\end{aligned}$ & $\begin{array}{l}m_{r}, m_{s}, m, m_{l}, m_{p} \text { and } m_{g}: \text { mass of root, leaf } \\
\text { sheath, clum, leaf blade, panicle vegetative com- } \\
\text { ponent, and gain, respectively; } r_{r}, r_{s}, r_{c}, r_{l}, r_{p} \text { and } \\
r_{g}: \text { respiration coefficient for each structure }\end{array}$ \\
\hline Nitrification & Nitrification_rate $=(\Delta t / 25)^{*} 0.03175\left[N H_{4}^{+}-N\right]^{1.1417}$ & At: the length of a time step \\
\hline Clay $\mathrm{N}$ fixation rate & $\Delta$ Fixed_N $N H_{4}^{+}=\mathrm{Cl}^{*}\left[\mathrm{NH}_{4}^{+}-\mathrm{N}\right]$ & $C l$ : coefficient \\
\hline
\end{tabular}


Table 2-contd

Clay $\mathrm{N}$ release rate

Plant uptake

Root distribution

Total carbohydrate and nitrogen demand

Demand by the

ith cohort

Panicle growth rate

$\mathrm{N}$ recovery

$\mathrm{N}$ export
$\Delta$ Released_N $H_{4}^{+}=C 2^{*}\left(\left[\right.\right.$ Fixed_NH $\left.\left.H_{4}^{+}-N\right]-148\right)$

Uptake $_{i}=0 \cdot 503^{*}\left[N H_{4}^{+}-N_{i}\right] /\left(1 \cdot 35+\left[N H_{4}^{+}-N_{i}\right]^{*}\right.$ Root_area $_{i}$

$P_{x}=\frac{\lambda^{\text {nodes }}(x-\theta)^{\text {nudes }-1} e^{-\lambda(x-\theta)}}{\Gamma(\text { nodes })}$

$D C_{-}$total $=\sum_{j=1}^{12} D C_{-}$tiller $_{j}$

$D C_{-}$tiller $r_{j}=\sum_{k=1}^{n} \sum_{i=1}^{l_{k}} D C_{-} m_{j, k, i}$

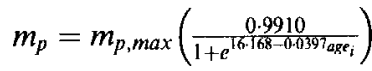

$I m p t_{-} N_{i}+\left(\text { Max }_{-} N-\text { Curt }_{-} N_{i}\right)^{*}$ Mass $_{i}{ }^{*} e^{-a A g e_{i}}$

$\operatorname{Expt}_{-} N_{i}=\left(\text { Curt }_{-} N_{i}-\text { Min_N }_{-}\right)^{*}$ Mass $_{i}^{*}\left(1-e^{-b A g e_{i}}\right)$
C2: coefficient

Root-area,: the root surface areas in the ith soil layer

nodes: the number of maintiller nodes, $\theta$ : the planting depth $(\mathrm{cm}) ; \lambda$ : a scale parameter; $\Gamma$ (nodes): a gamma function

DC_tiller: demand of the ith tiller cohort

$D C_{-} m_{j, k, i}:$ the demand for carbohydrate by the ith age-class of the kth structure type, within the $j$ th tiller age-cohort; $l_{k}$ : the maximum number of age classes for the kth structure

$m_{p, m a x}:$ the maxim panicle vegetative mass; $\operatorname{age}_{i}$; the degree days from differentiation

$\operatorname{Max} N$ : maximum potential nitrogen content; Curt_N $N_{i}$ : current nitrogen content; $\operatorname{Mass}_{t}\left(\mathrm{~g} \mathrm{~m}^{-2}\right)$ : mass of the ith age class of a structure; Age $_{i}$ : the physiological age of the ith age class; $\boldsymbol{a}$ : coefficient

$\operatorname{Min}_{-} N_{i}$ : the minimum nitrogen content; 6: coefficient 
Table 2-contd

\begin{tabular}{|c|c|c|}
\hline Process & Equation & Descriptions \\
\hline Priority & $P_{i}=\frac{m_{i, s} / m_{i, n s}}{\max \left(m_{i, s} / m_{i, n s}\right)}$ & $\begin{array}{l}m_{i, s} \text { and } m_{i, n s}: \text { either the final mass or the rate of } \\
\text { mass increase of the ith category growing under } \\
\text { physiological stress and under non-stressed con- } \\
\text { ditions, respectively }\end{array}$ \\
\hline $\mathrm{N}$ effect & $N_{-} \operatorname{coef}=\left\{\begin{array}{cl}1 & \text { if } N \geq N_{c} \\
\left(\frac{N}{N_{c}}\right) & \text { Otherwise }\end{array}\right.$ & Nand $N_{c}:$ the current and critical nitrogen content \\
\hline S/D effect & $S D_{-}$coef $=\left\{\begin{array}{cc}1 & \text { if } \min \left(S D_{n}, \mathrm{SD},\right)>1 \\
\left(\min \left(S D_{n}, S D_{c}\right)\right) & \text { Otherwise }\end{array}\right.$ & $\begin{array}{l}\mathrm{SD} \text {, and } S d_{c}: \text { the potential nitrogen and carbo- } \\
\text { hydrate supply/demand ratio }\end{array}$ \\
\hline Node production rate & $\Delta$ Node $=\Delta$ Node $_{\max }{ }^{*} N_{-}$coef $^{*} S D_{-}$coef & $\Delta$ Node $_{\max }:$ the maximum node production rate \\
\hline Growth & 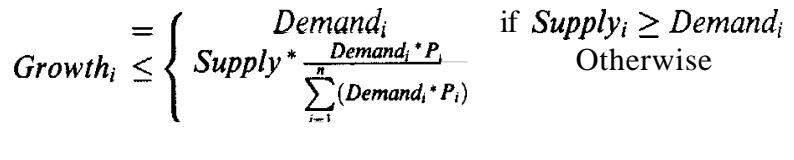 & $\begin{array}{l}\text { Demand;: the demand of the ith category; } \\
\text { Supply } y_{i} \text { the metabolite supply for the ith } \\
\text { category }\end{array}$ \\
\hline
\end{tabular}


calculated based on a discretization of Beer's Law (Monsi and Saeki, 1953), where the layering of leaf age classes within the canopy was estimated from field data. The effect of photosynthetically active radiation on the potential photosynthetic rate was estimated using data from Tanaka et al. (1966), scaled to a maximum photosynthetic rate of $31.57 \mu \mathrm{mol} \mathrm{CO}_{2} \mathrm{~m}^{-2}$ leaf area $\mathrm{s}^{-1}$ (Bouhache and Bayer, 1993; Sinclair and Horie, 1989). The data were scaled to correct for a consistent bias of earlier rice photosynthesis studies (Yoshida, 1981). Photosynthetic efficiency is a function of temperature (Huang et al., 1990) and leaf nitrogen content $\left(N_{l}\right)$ (Dingkuhn et ai., 1990). However, if the demand for carbohydrate is less than the potential supply, the gross photosynthetic rate is equal to the demand rate, reflecting carbohydrate supply driven photosynthesis feedback inhibition.

\section{Respiration}

Respiration in RICEPSM is separated into maintenance and growth respiration. Maintenance respiration is a temperature and mass dependent process with $Q_{10}=2$ (Liang et $\boldsymbol{a l . ,}$ 1986; Tanaka et al., 1966). Different structures have different physiological activities and therefore different respiration rates (Hesketh $\boldsymbol{e t}$ al., 1971; Penning de Vries and van Laar, 1982). At $20^{\circ} \mathrm{C}$, leaves require $1.71 \%$ of their carbohydrate mass for daily maintenance respiration (Okano et al., 1984). Stems, roots and reproductive structures are assumed to have 75, 25 (Iwaki, 1975, as cited by Graf et al., $1990 \mathrm{~b}$ ), and $50 \%$ (Graf et $\boldsymbol{a l} ., 1990 \mathrm{~b}$ ) of the per mass unit basis respiration rate of leaves, respectively. Growth respiration is treated as a function of photosynthetic activity (McCree, 1974). The coefficient for growth respiration is 0.27 (Yoshida, 1981). This means that $1 \mathrm{~g}$ of photosynthate not consumed by maintenance respiration produces $0.73 \mathrm{~g}$ dry mass.

\section{Soil nitrogen transformation}

The soil was divided into 10 layers, each $10 \mathrm{~cm}$ in thickness. The soil nitrogen balance for both $\mathrm{NH}^{+}{ }_{4}-\mathrm{N}$ and $\mathrm{NO}_{3}{ }^{-}-\mathrm{N}$ was estimated each time step for each layer, taking into account mineralization, nitrification, denitrification, clay fixation, volatilization, and plant uptake (Standford et al., 1975; Gilmour, 1984; Gilmour et al., 1985; Jayaweera and Mikkelsen, 1990) All soil layers are assumed to be reduced except for the top $1 \mathrm{~cm}$ of the first soil layer, which is oxidized. Nitrogen transformation and uptake is calculated for each soil layer.

The method developed by Gilmour et al. (1985) is used to estimate the net rate of mineralization and immobilization. The relation between nitrification rate and the concentration of $\mathrm{NH}^{+}{ }_{4}-\mathrm{N}$ was estimated from data in Turner (1979). The fixation of ammonium $\mathrm{N}$ by clay and organic matter is assumed to be a reversible process between fixed $\mathrm{NH}^{+}{ }_{4}-\mathrm{N}$ and free $\mathrm{NH}^{+}{ }_{4}-\mathrm{N}$ in the 
soil (Datta et al., 1987; Keerthisinghe et al., 1984; Schnier et al., 1987). The $\mathrm{NH}^{+}{ }_{4}-\mathrm{N}$ fixation rate is assumed to be a function of free $\mathrm{NH}^{+}{ }_{4}-\mathrm{N}$ concentration, while the $\mathrm{NH}^{+}{ }_{4}-\mathrm{N}$ release rate is a function of the fixed $\mathrm{NH}^{+}{ }_{4}-\mathrm{N}$ concentration.

\section{Plant nitrogen uptake}

Nitrogen uptake from the ith soil layer by a growing root system is described by the Michaelis-Menten equation (Youngdahl et al., 1982), and is a function of nitrogen concentration and root surface areas in the ith soil layer. The production of new roots at a particular depth during a time step is estimated using a three parameter Gamma distribution, as a function of node production and planting depth. The kinetics of $\mathrm{NO}_{3}{ }^{-}-\mathrm{N}$ uptake is similar to that of $\mathrm{NH}^{+}{ }_{4}-\mathrm{N}$. However, since the presence of $\mathrm{NH}^{+}{ }_{4}-\mathrm{N}$ inhibits the uptake of $\mathrm{NO}_{3}{ }^{-}-\mathrm{N}$ (Youngdahl et al., 1982), $\mathrm{NO}_{3}{ }^{-}-\mathrm{N}$ was assumed to be taken up by plants only when the uptake of $\mathrm{NH}^{+}{ }_{4}-\mathrm{N}$ could not satisfy the demand by the plants.

\section{Potential carbohydrate and nitrogen demand}

The potential growth rates for leaves, root, culm, leaf sheath, and grain were estimated from the field experiments. Since main tiller vegetative growth is normally not source limited, the maximum potential mass of each structure type for all tiller age-cohorts is assumed to be the average observed maximum mass of the same structure type for the main tiller (age-cohort 1), except for grains, which are produced during a period of carbohydrate and nitrogen supply stress. The maximum mass for individual grain was estimated as the mean mass of the largest five grains observed from a sample of 100 grains, with the relative growth rate of grain estimated from destructively sampling panicles throughout their development. The maximum mass for the panicle vegetative component and for spikelets were estimated from the panicle tagging data, while published data (Nagai, 1959) were used to estimate panicle vegetative growth as a function of degree days from panicle differentiation.

Nitrogen dynamics in rice is complex and some simplifying assumptions were made: (1) each structure type has a maximum and minimum potential nitrogen content, (2) newly formed mass has the ability to reach its structure's maximum potential nitrogen content, and (3) the nitrogen demand for newly formed mass is proportional to the growth of each structure, suggesting an optimal nitrogen to carbohydrate ratio in plant tissues (Dingkuhn et al., 1990).

\section{Remobilization}

If the potential carbohydrate supply is less than the corresponding demand, a maximum of $30 \%$ of non-structural carbohydrate is assumed to be 
remobilized each $40^{\circ} \mathrm{D}$ time step. Remobilization of carbohydrates is processed using the same approach as described in the Metabolite allocation priority section. Previous research has shown that nitrogen is exported from mature leaves and redistributed to developing organs (Mae and Ohira, 1982; Makino et al., 1984). However, nitrogen also continues to be imported into mature leaves during the period of net nitrogen export (Mae et al., 1983). If the potential supply of nitrogen is greater than the demand required to produce new tissues, referred to as growth demand, a structure can recover nitrogen if its nitrogen content is less than its maximum potential content. The maximum amount of nitrogen imported into the ith age-class of a structure type is assumed to be a function of a structures mass and age, and the difference between its maximum potential nitrogen content and its current nitrogen content. If the potential supply is less than the growth demand, remobilizable nitrogen can be exported from structures having a lower allocation priority to satisfy or partially satisfy growth demand of higher priority structures. The maximum amount of nitrogen exported from a structure is also assumed to be a function of a structures mass and age, and the difference between its current nitrogen content and its minimum potential nitrogen content.

\section{Metabolite allocation priority}

RICEPSM uses a tiered metabolite allocation scheme: (1) metabolite allocation among tiller age-cohorts, (2) allocation among structures within a tiller age-cohort, and (3) allocation among age-classes within a structure type within a tiller cohort. At each level, the allocation priorities were estimated from the field experiments and from published data (Tanaka et al., 1964; IRRI, 1986), based on the method of Wilson and coworkers (Wilson and Gutierrez, 1980; Wilson and Waite, 1982; Wilson et al., 1987a,b; Pickett et al., 1989).

\section{Organ initiation}

Rice has the property of synchronous initiation of a leaf blade, a leaf sheath, a culm, a tiller, and associated roots (Yoshida, 1981; Liang et al., 1986). The maximum node production rate was estimated from the field data, by regressing the first four node estimates against cumulative degree days. When the $n$th node is initiated, the $n$th leaf blade, $(\mathrm{n}-1)$ leaf sheath, $(n-2)$ culm, and $(n-3)$ th tiller and roots are born. However, when rice plants have fewer than four nodes, the main tiller roots may not follow this rule (Liang et al., 1986). When the last node is initiated, the panicle vegetative component and its grain are initiated. The number of spikelet positions per tiller was estimated as a function of the tiller's mass and rice population density (main tillers plus subtillers) at the time of panicle differentiation. 
Analyses of published data (Liang et al., 1986) suggests that the node production rate is a function of the ratio of the nitrogen content $(N)$ in the plant and a critical nitrogen content $\left(N_{\mathrm{c}}\right)$ below which the rate decreases. The rate of node production is also affected by carbohydrate and nitrogen metabolic stress. With only limited information available for a mechanistic interpretation of carbohydrate and nitrogen supply/demand mediated node production, an assumption was made that node production is primarily governed by the rate limiting stress factor (either carbohydrate or nitrogen).

\section{Organ growth}

For each time step, each structure that had the potential to grow received some energy, with the amount received being a function of a structure's potential growth rate, its priority for metabolites, and the availability of carbohydrate and nitrogen to meet demands for growth.

\section{Organ senescence}

Nitrogen deficiency hastens senescence (Dingkuhn et al., 1990). All structures within an age class senesce if the nitrogen content is lower than its minimum critical nitrogen content (van Keulen, 1978). Nitrogen deficiency induced tiller senescence was assumed to only occur prior to a tiller initiating panicle development. The senescence rate of a tiller age-cohort was assumed to be a function of its age and the rate limiting stress factor (either nitrogen or carbohydrate). As tillers senesce, the associated non-structural carbohydrates within the culm, leaf sheath, leaf blade, and root tissues are remobilized. The rates for spikelet degeneration and grain abortion are a function of carbohydrate and nitrogen stress occurring during the period from panicle differentiation to spikelet fertilization.

\section{Meteorological variables}

Daily maximum and minimum air temperatures, and solar radiation were recorded at the Texas A\&M University System Agricultural Research and Extension Center at Beaumont. A subroutine obtained from Wilson et al. $(1987 b)$ was used to estimate hourly temperature and solar radiation from daily data.

\section{Model parameterization, verification, and validation}

The goodness of fit of the simulation model to observed data was evaluated using the coefficient of multiple determination $\left(R^{2}\right)$, which measures the proportion of variability for single and multiple data types that was explained by the simulation model. Goodness of fit was evaluated across 
sampling dates for 13 data types obtained from the 1992 and 1993 destructive sampling experiments: total dry mass, number of tillers, number of nodes per main tiller, and mass of root, stem, leaf blade, panicle vegetative component, and grain, for the main tiller and collectively for the subtillers (eqn (1)):

$$
R^{2}=1-\frac{\sum_{j} S S E_{j} / S_{j}^{2}}{\sum_{j} S S T O_{j} / S_{j}^{2}}
$$

where $S S T O_{j}$ is the observed variation for thejth data type corrected for the mean, $S S E_{j}$ is the amount of variability for thejth data type not explained by the model, and $S_{j}^{2}$ is the variance of thejth data type.

The 1992 and 1993 destructive sampling data sets were used to verify and validate the model, respectively. A critical value $\left(R_{c}{ }^{2}=0.85\right)$ was used to test overall goodness of fit. When $R^{2}$ was greater than the $R_{c}{ }^{2}$, the model was considered verified with respect to its fit to a data set, if compared with a data set used to parameterize the model; or validated, if compared with an independent data set. After the model was verified or validated against a data set, the previously unused data set was used to evaluate the goodness of fit. If the model failed to adequately fit a data set, the parameterization and analysis cycle was repeated until the model was verified or validated against both data sets. Once a data set has been used for parameterization or verification, it could be used to reparameterize the model but was no longer used for validation.

\section{RESULTS}

\section{Model parameterization, verification, and validation}

Table 3 summarized the parameters and functions estimated from the field experiments and used to parameterize the simulation model. Table 4 summarized the accuracy of the initially parameterized model at simulating the seasonal dynamics of the 13 data types. The fit of the simulation model to the 1992 destructive data set was separated into early-, mid-, and late-season for the growth and development of leaf, stem, and root mass, numbers of nodes per tiller and number of tillers. These three periods roughly corresponded to the time intervals from planting to panicle differentiation, from panicle differentiation to heading, and from heading to the final sample. For both the vegetative component of the panicle and its grain, early, mid, and 
TABLE 3

Parameters and Functions Estimated from the Field Experiments

\begin{tabular}{|c|c|c|}
\hline Parameters & Value or function & Unit \\
\hline ANode $\max$ & 0.6280 & Node At-' \\
\hline$\varepsilon^{a}$ & 0.1096 & None \\
\hline$m_{l \cdot \max b}$ & 0.2540 & g leaf ${ }^{-1}$ \\
\hline$m_{c, \max }$ & 0.3108 & g node ${ }^{-1}$ \\
\hline$m_{s, \max }$ & 0.3789 & g node- \\
\hline$m_{r, \max }$ & 0.1012 & g node-' \\
\hline$m_{p, \max }$ & 0.1200 & g panicle-' \\
\hline$m_{g, \max }$ & 0.0321 & g grain-' \\
\hline \multirow{2}{*}{\multicolumn{2}{|c|}{$\begin{array}{l}\text { Number of grains } 232.52+59.11 m_{t}-0.413 \text { Density } \\
\text { Specific leaf area }-1.7248 e-11 D^{3}+6.2908 e-8 D^{2}-7.5313 e-5 D^{d}+0.04987\end{array}$}} & grains panicle- \\
\hline & & $\mathrm{m}^{2} \mathrm{~g}^{-1}$ \\
\hline
\end{tabular}

${ }^{a} \varepsilon$ is the probability of aging 2 age classes each time step for leaf, stem, root, vegetative panicle and grain.

${ }^{b} m_{l, \max }$ is mass for the largest leaf of main tiller.

' $m_{t}$ and density are the tiller mass (g tiller-'), and tiller density (tillers $\mathrm{m}^{-2}$ ) at panicle differentiation.

${ }^{d} \mathrm{D}$ is degree-days $\left(>\mathbf{1 0}^{\circ} \mathbf{C}\right)$ from planting.

TABLE 4

The Relative Departure of Simulated from Observed Data for the 1992 Verification Data Set ${ }^{a}$

\begin{tabular}{lcccccc}
\hline & \multicolumn{3}{c}{ Maintiller growth } & stage & \multicolumn{3}{c}{ Subtiller growth stage } \\
\cline { 2 - 6 } Data type & Early- & Mid- & Late- & Early- & Mid- & Late- \\
\hline Note number & -- & 0 & 0 & & & \\
Tiller number & 0 & + & ++ & ++ & $+/-$ & -- \\
Leaf mass & 0 & - & 0 & ++ & ++ & + \\
Stem mass & 0 & - & 0 & ++ & ++ & + \\
Root mass & - & -- & - & + & -- & -- \\
P. vegetative mass & 0 & + & ++ & + & + & - \\
Grain mass & + & + & ++ & & & \\
Total mass & & & & & & +
\end{tabular}

${ }^{a} 0$ the model closely simulated the observed data, + and ++ model overestimated data type by $5-10 \%$ and $>10 \%$, respectively, - and -- underestimated by $5-10 \%$ and $>10 \%$, respectively.

late roughly corresponded to three successive $400^{\circ} \mathrm{D}$ time interval starting from panicle differentiation. A 0 in Table $\mathbf{4}$ indicates that the model closely simulated the observed data. A + or - indicates that the model overestimated or underestimated the data type by 5 to $10 \%$. A ++ or -- indicates that the model consistently departed by greater than $10 \%$ from the observed data during the indicated time period. 
The model failed to pass the verification step following initial parameterization. An analysis of Table 4 indicated that the model accurately simulated number of nodes and main tiller mass during the early- and midseason periods. However, subtiller mass was overestimated, while main tiller root mass and panicle vegetative mass were underestimated. As assumption had been made that the maximum potential mass of a structure was the same for all structures of a type that were initialized at the same time, for all tiller cohorts. An analysis of the 1992 leaf mass data showed that the maximum mass for the first 3 to 4 leaves decreased with each successive tiller cohort. An assumption had also been made that this decrease was largely due to leaves on young subtillers having a lower potential for growth. An error was also identified with the procedure used to initiate panicle differentiation. When the number of nodes per main tiller reached the average node at which panicle differentiation occurred (11 for Gulfmont), all tillers had been triggered to initiate panicle development. This approximation was incorrect since 10 to 14 days are required to complete panicle differentiation for all the tillers in a field (Liang et al., 1986; Yoshida, 1981). Analysis of the node production data showed that the number of nodes per main tiller in each sample followed a normal distribution with a standard deviation of 0.498 . In the reparameterized model, for each time step, the proportion of main tiller and subtillers reaching panicle differentiation was estimated as the probability of a main tiller having $\geq 11$ nodes.

This change resulted in improvement to the simulated output, but the model again failed the verification test. The primary cause for the lack of fit of the simulated data to the observed data was traced to the function which controlled tiller initiation and senescence, and the functions which controlled spikelet production and abortion. The initially parameterized model assumed that tiller production and survival were at a maximal rate when the carbohydrate $S / D$ ratio was $\geq 1 \cdot 0$. However, the destructive sampling data indicated that the rate of tiller production and the tiller survival rate both began to decrease prior to the time when either carbohydrate or nitrogen stress were simulated to occur. This may suggest that localized source-sink imbalances may reduce tiller initiation and increase mortality when whole plant estimates of carbohydrate production appear sufficient to meet total plant demands. Or, it may indicate that the plant is able to detect changing carbohydrate levels as carbohydrate stress is approached, possibly by detecting the gradual release of photosynthesis from feedback inhibition as carbohydrate demand rapidly approaches carbohydrate supply. The fit of the simulated model was improved by changing the potential carbohydrate S/D ratio at which maximum tiller initiation and survival occurs from 1.0 to 1.1. The lack of fit of the spikelet data was due to having assumed that spikelets initiated development at the time of panicle differentiation, which coincides 
with emergence of the third leaf from the flag leaf. Spikelet production on a differentiating panicle actually occurs at the time of the emergence of the 2nd leaf from the flag leaf (Yoshida, 1981). This correction only partially accounted for the discrepancy between observed and simulated spikelet production and survival. The simulated spikelet numbers overestimated the observed data and underestimated spikelet mortality, particularly during the period of spikelet production and grain filling. This appeared largely due to the lack of inclusion of the direct impact of high temperatures on spikelet abortion as had been documented by Liang $\boldsymbol{e t}$ al. (1986). As a result, eqn (2) was added to integrate the impact of daily temperatures on spikelet abortion:

$$
\text { Abortion }=\left\{\begin{array}{cc}
0.00025(T-27)^{2} & T \geq 27 \\
0 & 24<\mathrm{T}<27 \\
0.0025(24-T)^{2} & T \leq 24
\end{array}\right.
$$

where Abortion is the proportion of spikelets aborted per day, and $\mathrm{T}$ is a daily mean temperature $\left({ }^{\circ} \mathrm{C}\right)$ during the time from spikelet differentiation to 10 days after flowering.

Model output was significantly improved with the criteria for model verification having been met (Table 5). The verified model was then used to simulate rice growth and development using the 1993 agronomic and weather data, and the simulated output compared with the 1993 data set. The model met the validation criteria without further modification (Table 5). Although the model was verified with the 1992 data set and validated with the 1993 data set, comparison of the simulated results to both the 1992 and 1993 data sets showed that simulated leaf and stem mass were greater than the observed mass for both years following the initiation of grain filling. These discrepancies suggest that the model either overestimated leaf and stem initiation, overestimated the growth rate of individual leaves and stem segments, underestimated remobilization of mass from these structures to other structures, or overestimated leaf and stem longevity. Comparison of the number of simulated nodes per meter square (cumulative leaf or stem initiation) with observed number of nodes in 1992, for both the main tillers and subtillers, indicated that stem and leaf initiation were simulated accurately $\left(r^{2}=0.92\right)$. Similarly, comparison of simulated and observed growth rates for late season produced leaves indicated close fit to the 1992 leaf data $\left(r^{2}=0.96\right)$. Remobilization of nonstructural carbohydrate and nitrogen were each estimated from data obtained from the literature (Andrews, 1990; Schnier $e t$ ai., 1990). As a result, their accuracy can not be directly evaluated. However, the close fit of the simulated and observed early- and mid-season leaf mass data suggests a lack of discrepancies comparing the literature derived estimates with the estimates derived from the 1992 and 1993 experiments. 
TABLE 5

$R^{2}$ Values for Overall Model Fit and for Each Data Type for the 1992 and 1993 Data Sets

\begin{tabular}{|c|c|c|c|c|c|c|c|c|c|c|c|c|c|c|}
\hline \multirow[t]{2}{*}{ Simulation } & \multicolumn{2}{|r|}{ Total } & \multicolumn{2}{|l|}{ Tiller } & \multicolumn{5}{|c|}{ Main tiller mass $\left(\mathrm{g} \mathrm{m}^{-2}\right)$} & \multicolumn{5}{|c|}{ Subtiller mass $\left(\mathrm{g} \mathrm{m}^{-2}\right)$} \\
\hline & Overall & Mass & $m^{2}$ & Node ${ }^{a}$ & Panicle $^{b}$ & Grain & Leaf & Stem & Root & Panicle & Grain & Leaf & Stem & Root \\
\hline Verification & 0.69 & 0.82 & 0.60 & 0.97 & 0.69 & 0.68 & 0.76 & 0.89 & 0.69 & 0.00 & 0.81 & 0.56 & 0.74 & 0.40 \\
\hline Verification" & 0.77 & 0.88 & 0.80 & 0.97 & 0.76 & 0.74 & 0.76 & 0.89 & 0.69 & 0.42 & 0.81 & 0.68 & 0.80 & 0.57 \\
\hline Verification $^{\mathrm{d}}$ & 0.83 & 0.90 & 0.88 & 0.98 & 0.79 & 0.83 & 0.81 & 0.88 & 0.80 & 0.64 & 0.81 & 0.73 & 0.88 & 0.73 \\
\hline Verification' & 0.88 & 0.94 & 0.94 & 0.98 & 0.79 & 0.88 & 0.84 & 0.88 & 0.85 & 0.70 & 0.93 & 0.86 & 0.89 & 0.81 \\
\hline Validation 1993 & 0.87 & 0.97 & 0.84 & 0.99 & 0.86 & 0.92 & 0.92 & 0.91 & 0.96 & 0.64 & 0.95 & 0.75 & 0.87 & 0.65 \\
\hline Reverification 1993' & 0.89 & 0.99 & 0.84 & 0.99 & 0.87 & 0.92 & 0.95 & 0.96 & 0.95 & 0.83 & 0.94 & 0.82 & 0.90 & 0.77 \\
\hline
\end{tabular}

${ }^{a}$ Number of nodes per main tiller.

${ }^{b}$ Panicle vegetative component.

"Addition of tiller cohort leaf potential size function, and distributed panicle differentiation node.

${ }^{d}$ Change to tiller survival function, correction to spikelet initiation function.

'Addition of temperature spikelet abortion function.

${ }^{f}$ Correction to leaf duration estimate, addition of metabolic stress main tiller leaf sheath death function. 
The lack of discrepancy between the simulated and estimated values with these components, suggests an error with the estimated leaf longevity. The original analysis of the 1993 life table data showed that leaf longevity was a function of nodal position. In addition, published data showed that leaf longevity was also a function of leaf nitrogen concentration (van Keulen, 1978; Tanaka et al., 1964). Reanalysis of the 1993 life table data showed that the maximum leaf age at senescence for the last four leaves on each main tiller and subtiller $\left(960^{\circ} \mathrm{D}\right)$ had inadvertently been used for the mean leaf longevity $\left(880^{\circ} \mathrm{D}\right)$. Similarly, reanalysis of the destructive sampling data suggested that the stem discrepancy was due to the observed main tiller and subtiller stem mass decreasing more rapidly than the simulated mass. The 1992 and 1993 destructive sampling data showed that stem mass from the final sample ranged from 63 to $100 \%$ of the maximum stem mass depending on the tiller cohort, with the main tiller stem mass decreasing to the greatest degree followed in order by the successivetiller cohorts. These data imply that the main tiller stem had a relatively greater amount of mass remobilized to grain, and probably greater leaf sheath senescence. The greater reduction in main tiller stem mass was probably due to its greater sink size (number of spikelets per panicle). Although RICEPSM calculates sink size for each tiller age-cohort, it does not maintain separate metabolic pools for each tiller cohort. To capture the differential remobilization contrasting tiller cohorts, each time step that the potential carbohydrate $\mathrm{S} / \mathrm{D}$ ratio was less than one, $3 \%$ of leaf sheath mass was removed from all leaf sheath age classes for the main tiller cohort, reflecting an increase in sheath senescence. The reparameterized model was then reverified against both the 1992 and 1993 data sets (Table 4).

\section{Simulated vs observed data}

The verified and validated rice model simulated reasonably well the node production rates comparing the two years $\left(r^{2}=0.98, n=8,1992 ; r^{2}=0.99\right.$, $n=13$, 1993). Before panicle differentiation, a node was produced about every 70 to $80^{\circ} \mathrm{D}$; afterwards every 100 to $140^{\circ} \mathrm{D}$. The $\mathrm{R}^{2}$ for the goodness of fit for number of nodes per main tiller was 0.97 and 0.99 for the 1992 and 1993 data, respectively. Accuracy in simulating tiller node production is critical to model performance since initiation of each structure type and each subtiller, and their subsequent growth are related to the initiation of the associated node. The lower rate of early node production during 1992 (on a degree-day time scale) was largely a result of increased temperatures due to the later planting date during that year, resulting in higher respiration rates and lower metabolic efficiency.

The number of tillers increased rapidly until a maximum number was reached at 930 and $750^{\circ} \mathrm{D}$ from planting, in 1992and 1993, respectively (Fig. 1). 


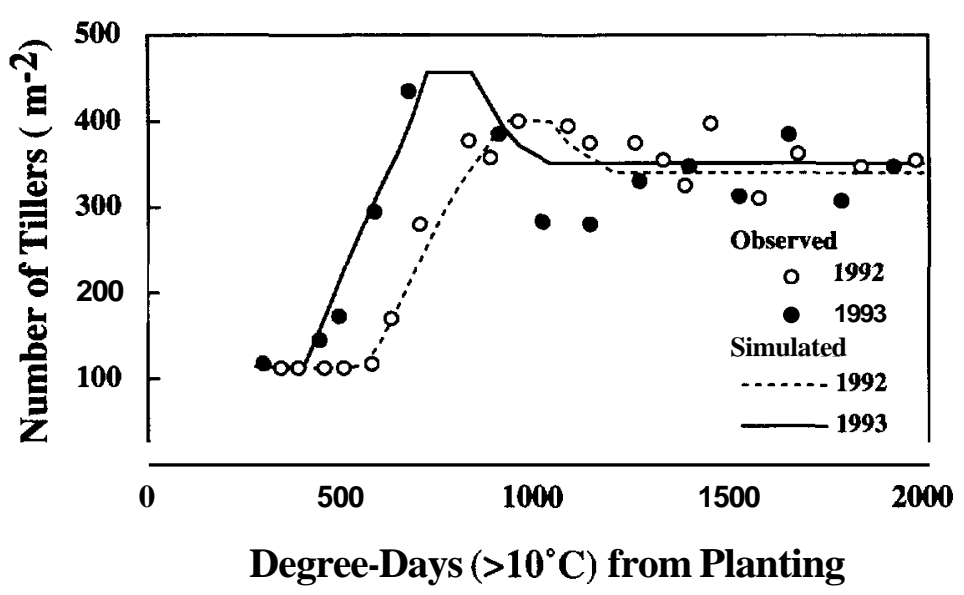

Fig. 1. Observed and simulated number of tillers (tillers $\mathbf{m}^{-2}$ ) for the 1992 and 1993 experiments.

Analysis of the simulated seasonal carbohydrate supply/demand patterns suggests that the difference in tillering was due to transitory carbohydrate stress occurring just prior to the time of tiller initiation during 1992 (Fig. 2(A)), resulting from higher temperatures and elevated respiration rates experienced at that stage of crop growth. While tiller initiation appeared to be largely controlled by carbohydrate stress, the mid-season pattern of tiller senescence appeared to be caused by nitrogen stress (Fig. 2(B)). Although the simulated number of tillers in the late season was slightly higher than the observed data for the 1993 season, the model captured the seasonal dynamics of tiller initiation and senescence $\left(r^{2}=0 \cdot 84\right)$.

The rice model generally accurately simulated mass for leaf, stem, root, panicle vegetative component, and grain (Fig. 3), for the main tiller and subtillers (data not shown). However, in 1992, leaf mass was overestimated and root mass underestimated during grain ripening. In contrast, in 1993, root mass was overestimated for subtillers during grain ripening. Panicle vegetative mass for main tillers and subtillers were the least well simulated. The relatively poor fit of the simulation model to the panicle vegetative mass in 1992 appears due to rice blast (Pyricularia grisea Saccardo) affecting about $30-50 \%$ of the rice plants during grain filling. Comparison of the ratios of simulated to observed grain mass showed a higher ratio in 1992 (1.05) than in 1993 (0.93). In contrast, the comparable ratios for the panicle vegetative mass were lower in 1992 (0.87) than in 1993 (1.08). These results, although not conclusive, suggest that the rice blast may have inhibited transport of carbohydrates to the developing grain during 1992, causing carbohydrate loading in the panicle vegetative mass 'upstream' to the sites of partial phloem blockage. 


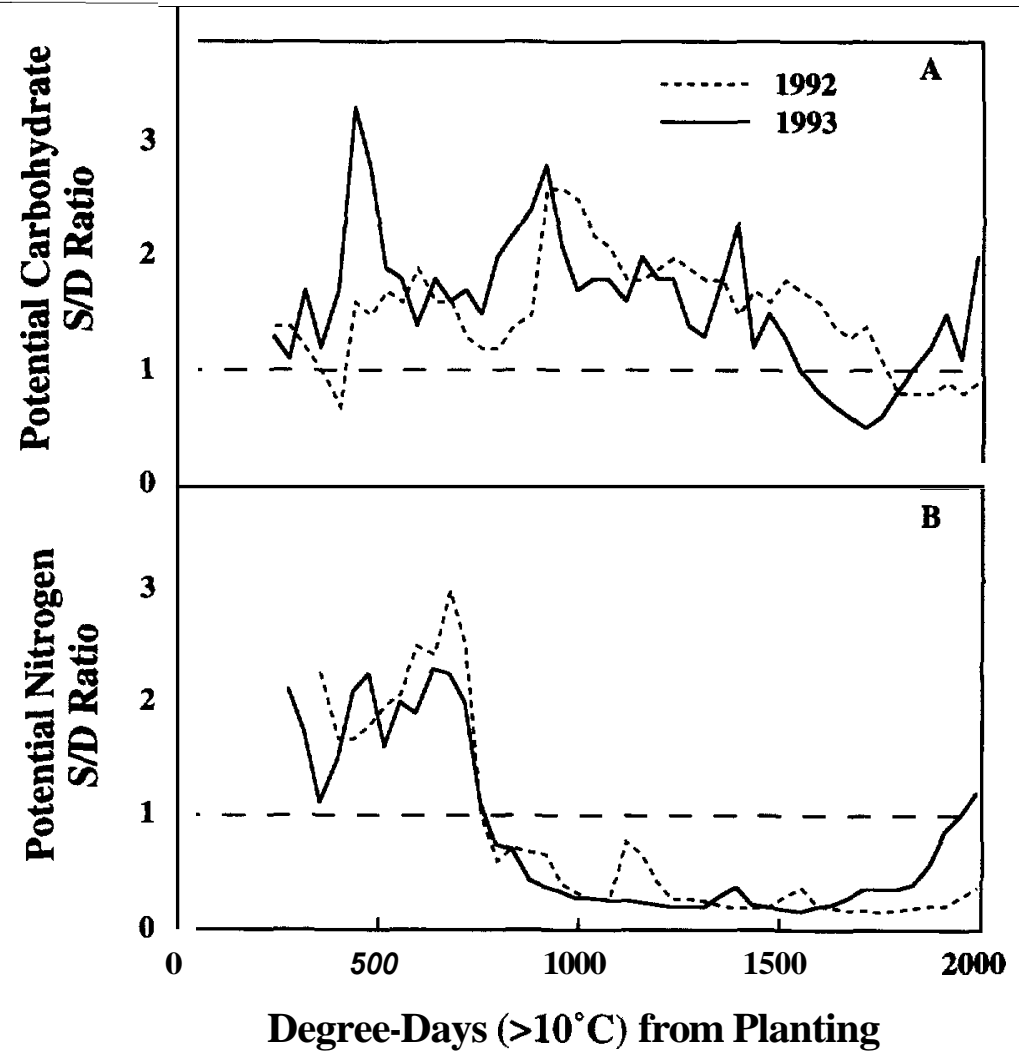

Fig. 2. (A) Simulated potential carbohydrate supply/demand S/D ratiom, and (B) simulated potential nitrogen S/D ratio for the 1992 and 1993 experiments.

\section{DISCUSSION}

The statistically rigorous parameterization, verification, and validation procedure forced us to examine in great detail each of the assumptions embedded within the model. As such, it improved our understanding of rice plant population dynamics. This activity has also resulted in a physiologically based model which has considerably potential for use in addressing the impact of physical and abiotic stresses on rice growth, development, and yield. The model's age-structure proved necessary for accurately capturing the distributed growth of the vegetative and reproductive structures. It also enabled us to discriminate the differential response of each age class of each plant part to stress, and will enable us to link RICEPSM with herbivore, pathogen, nematode, and weed population models. From a conceptual point of view, this approach can be used to study the dynamics of a range of cropping system.

The physiological detail imbedded within RICEPSM departs to the greatest degree from previously published rice simulation models in its tiller 


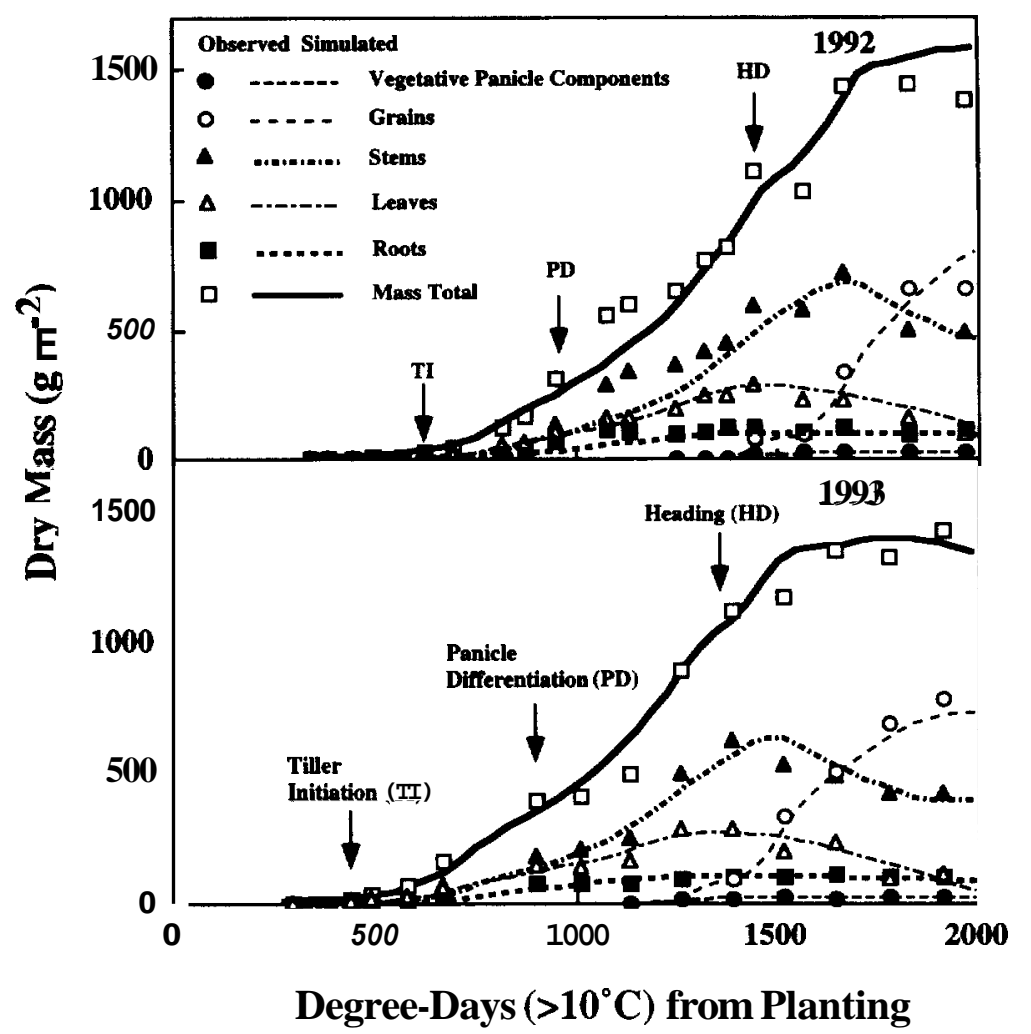

Fig. 3. Observed and simulated dry mass accumulation of panicle vegetative component, grain, leaf, leaf sheath, culm, root, and total dry mass for the 1992 and 1993 experiments.

cohort and plant organ age structure, and its metabolite partitioning structure. Only the model by Graf $\boldsymbol{e t}$ al. $(1990 a, b)$ had previously incorporated an age-structure that integrates variability in aging. Possibly the greatest distinction between our model and previously developed rice models is the inclusion of a statistically rigorous model parameterization, verification, and validation process. In most cases, authors of rice simulation models have concluded that their models were statistically validated based on the graphical fit of selected output to a data set from another year or location (McMennamy and O'Toole, 1983; Graf et al., 1990b; Miller et al., 1993), from data sets used to parameterize the model (Zhang and Chen, 1990), or by referencing obscure and often difficult to obtain proceedings articles. Although graphical comparison is the most straightforward and possibly the most commonly used method, the perceived level of deviation of simulated values from observed data depends on the scale chosen for presentation. For example, Miller $\boldsymbol{e}$ al. (1993) graphically compared simulated total mass, leaf, stem and grain mass with observed data, with the resultant fit appearing to 
be quite good. However, $r^{2}$ values estimated from data in Miller $\boldsymbol{e t}$ al. (1993) were $0.76(n=6), 0.30(n=6), 0.73(n=6)$, and $0.93(n=3)$, for above ground mass, leaf, stem, and grain mass, respectively; while $R^{2}$ across the four data types was 0.63 .

Salam et al. (1994) used the $r^{2}$ value of the linear regression between the simulated and observed mass to evaluate their model. This method gives the correct result only when the $\mathrm{Y}$ intercept of the regression line is zero, and when the slope of the regression is 1.0. Graf et al. (1991) proposed two statistics, a standardized bias $\boldsymbol{R}=\sum_{i=1}^{n}\left(y_{i}-x_{i}\right) / \sum_{i=1}^{n} x_{i}$, and a standardized mean square error $V=\sum_{i=1}^{n}\left(y_{i}-x_{i}\right)^{2} / \sum_{i=1}^{n} x_{i}^{2}$. The authors incorrectly concluded that

" $R$ quantifies the model's ability to reproduce the observed growth pattern", and that $V$ "reveals the model's tendency to generally over- or under-estimate field observations". The statistic $\boldsymbol{R}$ is flawed since negative deviations compensate for positive deviations. The statistic $V$ only measures the total square relative deviation which does not indicate whether the model over- or underestimates the observed data.

Willers et al. (1995) presented statistical methodology based on the generalized multiplicative interaction model (Milliken and Johnson, 1989) that could be used to test the fit of simulation models to a single response variable having a two-way unreplicated treatment structure. The generalized multiplicative interaction model is most appropriately used when an unreplicated two-factor analysis is biased due to a significant first-order interaction term. Because the first order interaction is used as the error term (fixed effect model) for such an analysis, it overestimates the true error when the interaction is significant, resulting in the significance of the main affects being underestimated (Zar, 1984).

The generalized multiplicative interaction model would have application to this research were the focus to have been on the difference between simulated and observed data for a single response variable, across two independent variables. However, the application of such an approach to each of the 13 response variables for each time that samples were taken, would have been analogous to conducting repeated t-tests, which would have resulted in major inflation of the $\alpha$ error rate. The resulting effect would be to conclude that a greater number of significant difference was present than was the case, resulting in an error opposite in direction to that which can occur when conducting non-replicated factorial analyses.

The verification-validation approach used in this paper has the advantage of enabling the individual and collective fit of multiple response variables to be examined. Furthermore, by analyzing the temporal 'fit' of the model, as 
contrasted with a single point in time analysis as presented by Willers et al. (1995), it can be argued that the robustness of the simulation model can be better evaluated.

The value of RICEPSM to the scientificcommunity will in part depend on how well this model performs across a range of plant types, physical and biotic stress levels, and geographical locations. The 1992 and 1993 experiments were planted May 8 and March 27, to insure that the temperatures experienced during vegetative and reproductive growth were quite different contrasting the two growing seasons. The mean temperature during the first month following planting was much warmer in $1992\left(\bar{x}=23.8^{\circ} \mathrm{C}\right)$ than in $1993\left(\mathrm{X}=18.0^{\circ} \mathrm{C}\right)$. In contrast, the mean temperature from heading to harvest was much lower in $1992\left(\bar{x}=25.8^{\circ} \mathrm{C}\right)$ than in $1993\left(\bar{x}=28.7^{\circ} \mathrm{C}\right)$. The excellent fit to both data sets suggests that the model captures the general effect of temperature on rice tiller population growth and development. Wilson et al. (1996) used RICEPSM to compare the yield response of 15 diverse rice types differing in the number of tillers produced, the node at which the panicle was initiated, the number of florets produced per panicle, and the average mass of each grain on the mature panicle, for each of two growing seasons (1994 and 1995). The yield of these lines varied from 492 to $1161 \mathrm{~g} \mathrm{~m}^{-2}$ in 1994 and 227 to $706 \mathrm{~g} \mathrm{~m}^{-2}$ in 1995, with harvest varying from 106 to 149 days after planting in 1994 and 113 to 158 days in 1995 , respectively. Grain yield for the very early and very late maturing recombinant lines was very similar in 1994 and 1995. In contrast, the intermediate maturating lines suffered extreme reductions in grain yield in 1995 contrasted with 1994. Simulation analyses by Wilson et al. (1996) strongly suggested that the reductions in yields for the mid-season maturing lines was largely due to carbohydrate depletion caused by high night temperatures during the middle of the 1995 summer months. Subsequent analysis of total non-structural carbohydrate levels showed a $23 \%$ reduction during the 1995 grain filling period contrasted with values obtained in 1994 (Samonte and Wilson, unpubl. data). The ability of RICEPSM to capture the yield variability and carbohydrate depletion across recombinant inbred lines representing a wide range of growth patterns is very encouraging. In a third analysis, $\mathrm{Wu}$ and Wilson (1997) simulated the response of rice to rice water weevil injury, using four years of data obtained from the literature. Each year had up to three treatments representing an untreated control, a single, and two insecticide applications to suppress the rice water weevil. The treatments resulted in a range of rice water weevil population densities. In this analysis, an average of $95 \%$ of the variation in grain yield and above ground biomass was explained by the model, contrasting to only 58\% of the variability explained by a multiple linear regression model. The general ability of RICEPSM to accurately capture rice's response to varietal differences, and 
physical and biotic stresses is encouraging. A statistically rigorous parameterization, verification, and validation approach that is applicable for use in evaluating other crop simulation models is presented.

\section{ACKNOWLEDGEMENTS}

The authors wish to thank Dr A. M. McClung, for help in conducting the field experiments at the Texas A\&M University System Agricultural Research and Extension Center at Beaumont, Texas, and Drs M. E. Makela, C. Fernandez, and R. Lascano for reviewing an earlier draft of this manuscript. This study was supported by grants to L. T. Wilson from the Texas A\&M University Research Enhancement Program, and from the Texas Rice Research Foundation.

\section{REFERENCES}

Allen J. C., (1976) Modified sine wave method for calculating degree-days. Environmental Entomology 5, 388-396.

Andrews, D. L. (1990) Characterization of differentially expressed mRNA sequences in rice (Oryza sativa $\mathrm{L}$.), cv. Lemont and correlation of their expression with total nonstructural carbohydrate content. Ph.D. dissertation, Texas A\&M University, College Station, TX.

Angus, J. F. and Zandstra, H. G. (1980) Climatic factors and the modeling of rice growth and yield. In Proceedings of a Symposium on the Agrometeorology of the Rice Crop, pp. 189-199. IRRI, Los Baiios, The Philippines.

Bouhache, M. and Bayer, D. E. (1993) Photosynthetic response of flooded rice (Oryza sativa) and three Echinochfoa species to changes in environmental factors. Weed Science 41, 611-614.

Chen, C. C., Turner, F. T. and Dixon, J. B. (1989) Ammonium fixation by highcharge smectitein selected Texas Gulf Coast soils. Soil Science Society of America Journal 53, 1035-1040.

Costello, T. A., VanDecender, K. W. and Ferguson, J. A. (1988) The Arkansas rice model: preliminary structure. ASAE Microfiche No. 88-4062.

Datta, S. K., Fillery, I. R. P., Obcemea, W. N. and Evangelista, R. C. (1987) Floodwater properties, nitrogen utilization, and nitrogen- 15 balance in a calcareous lowland rice soil. Soil Science Society of America Journal 51, 1355-1362.

Dingkuhn, M., Schnier, H. F., De Datta, S. K., Dorffling, K., Javellana, C. and Pamplona, R. (1990) Nitrogen fertilization of direct-seeded flooded vs. transplanted rice: 11. Interactions among canopy properties. Crop Science 30, 1284 1292.

Gilmour, J. T. (1984) The effects of soil properties on nitrification and nitrification inhibition. Soil Science Society of America Journal 48, 1262-1266.

Gilmour, J. T., Clark, M. D. and Sigua, G. C. (1985) Estimating net nitrogen mineralization from carbon dioxide evolution. Soil Science Society of America Journal 49, 1398-1402. 
Graf, B., Gutierrez, A. P., Rakotobe, O., Zahner, P. and Delucchi, V. (1990) A simulation model for the dynamics of rice growth and development. Part 11. The competition with weeds for nitrogen and light. Agricultural Systems 32, 367392.

Graf, B., Rakotobe, O., Zahner, P., Delucchi, V. and Gutierrez, A. P. (1990) A simulation model for the dynamics of rice growth and development. Part I. The carbon balance. Agricultural Systems 32, 341-365.

Graf, B., Dingkuhn, M., Schnier, F. and Coronel, V. (1991) A simulation model for the dynamics of rice growth and development. 111. Validation of the model with high-yielding varieties. Agricultural Systems 36, 329-349.

Gutierrez, A. P. and Wang, Y. (1976) Applied population ecology: models for crop production and pest management. In Proceeding of a Conference on Pest Management, ed. C. Norton and C. S. Holling, pp. 352. Laxenberg, Austria.

Hesketh, J. D., Baker, D. N. and Duncan, W. G. (1971) Simulation of growth and yield in cotton: respiration and the carbon balance. Crop Science 2, 394-398.

Huang, C. and Wang, T. D. (1986) Computer simulation of biomass production in rice community. Acta Agronomica Sinica 12(1), 1-8.

Huang, Y., Gao, L. Z. and Jin, Z. Q. (1990) A dynamic computer model for simulating photosynthetic production of rice canopies. Chinese Agriculture Meteorology 11(1), 10-15.

IRRI (1986) Progress Report for 1985. IRRI, Los Baños, The Philippines.

Jayaweera, G. R. and Mikkelsen, D. S. (1990) Ammonia volatilization from flooded soil systems: a computer model. Soil Science Society of America Journal 54, $1447-1468$.

Keerthisinghe, G., Mengel, K. and Datta, S. K. (1984) The release of nonexchangeable ammonium ( ${ }^{15} \mathrm{~N}$ labelled) in wetland rice soils. Soil Science Society of America Journal 48, 291-294.

Liang, L. (1983) Ecology of Rice. Chinese Agriculture Press, Beijing.

Liang, G.S., Muo, J. R. and Ran, C. F. (1986) Rice physiology and ecology. In Rice Cultivation in China, pp. 159-220. Chinese Academy of Agricultural Sciences. Chinese Agriculture Press, Beijing.

Mae, T. and Ohira, K. (1982) Relation between leaf age and nitrogen incorporation in the leaf of the rice plant (Oryza sativa L.). Plant and Cell Physiology 23, 1019 1024.

Mae, T., Makino, A. and Ohira, K. (1983) Change in the amount of ribulose biphosphate carboxylase synthesized and degraded during the life span of rice leaf (Oryza sativa L.). Plant and Cell Physiology 24, 1079-1086.

Makino, A., Mae, T. and Ohira, K. (1984) Relation between nitrogen and ribulose1, 5-biphosphate carboxylase in rice leaves from emergence through senescence. Plant and Cell Physiology 25, 429-437.

McCree, K. J. (1974) Equation for the rate of dark respiration of white clover and grain sorghum, as function of dry weight, photosynthetic rate, and temperature. Crop Science 14, 509-514.

McKendrick, A. G. (1926) The application of mathematics to medical problems. Proceedings Edinburgh Mathematical Society 44, 98-130.

McMennamy, J. A. and O'Toole, J. C. (1983) RICEMOD: a physiologically based rice growth and yield model. ZRPS $87,1-33$.

Miller, B. C., Foin, T. C. and Hill, J. E. (1993) CARICE: a rice model for scheduling and evaluating management actions. Agronomy Journal 85, 938-947. 
Milliken, G. and Johnson, D. (1989) Analysis of Messy Data. Vol. 2. Nonreplicated Experiments. Van Nostrand Reinhold, New York.

Monsi, M. and Saeki, T. (1953) Uber den lichtfaktor in den pflanzengesschaftenund seine bedeutung fui die stoffproducktion. Journal of Botany, Japan 14, 22-52.

Nagai, I. (1959) Joponica Rice: Its Breeding and Culture. Yokendo Ltd, Tokyo.

Okano, K., Tatsumi, J., Yoneyama, T., Kono, Y. and Totsuka, T. (1984) Comparison of the rates of ${ }^{15} \mathrm{NO}_{2}$ and ${ }^{13} \mathrm{CO}_{2}$ absorbed through a leaf of rice plants. Research Report from the National Institute for Environmental Studies, Japan 66, 59-68.

Penning De Vries, F. W. T. and Van Laar, H. H. (1982) Simulation of growth processes and the model BACROS. In Simulation of Plant Growth and Crop Production, ed. F. w. T. Penning De Vries and H. H. Van Laar, pp. 114-135. Pudoc, Wagenningen.

Pickett, C. H., Wilson, L. T., Flaherty, D. L. and Gonzalez, D. (1989) Measuring the host preference of parasites: an aid in evaluating biotypes of Anagrus Epos [HYM: Mymaridae]. Entomophaga 34, 551-558.

Plant, R. E. and Wilson, L. T. (1986) Models for age structural populations with distributed maturation rates. Journal of Mathematical Biology 23, 247-262.

Reddy, K. R. (1982) Nitrogen cycling in a flooded-soil ecosystem planted to rice (Oryza sativa L.). Plant and Soil 67, 209-220.

Ritchie, J. T., Alocilja, E. C., Singh, U. and Uehara, G. (1987) IBSNAT and the CERES-Rice model. In Weather and Rice, Proceedings of the International Workshop on the impact of weather parameters on growth and yield of rice, 7-10 April, 1986.pp. 270-279. IRRI, Los Baiios, The Philippines.

Salam, M. U., Street, P. R. and Jones, J. G. W. (1994) Potential production of Boro rice in the Haor region of Bangladesh: Part I. The simulation model, validation and sensitivity analysis. Agricultural Systems 46, 257-278.

Schnier, H. F., De Datta, S. K. and Mengel, K. (1987) Dynamics of ${ }^{15} \mathrm{~N}$-labelled ammonium sulfate in various inorganic and organic soil fractions of wetland rice soils. Biological Fertilizer Soils 4, 171-177.

Schnier, H. F., Dingkuhn, M., De Datta, S. K., Mengel, K. and Faronilo, J. E. (1990) Nitrogen fertilization of direct-seeded flooded vs. transplanted rice: I. Nitrogen uptake, photosynthesis, growth, and yield. Crop Science 30, 12761284.

Sinclair, T. R. and Horie, T. (1989) Leaf nitrogen, photosynthesis, and crop radiation use efficiency: a review. Crop Science 29, 90-98.

Singh, U. and Padilla, J. L. (1995) Simulating rice response to climate change. In Climate change and Agriculture: Analysis of Potential International Impacts, ed. G. A. Peterson, pp. 99-121. ASA Special Publication No. 59, Madison, WI.

Standford, G., Dzienia, S. and Vanderpol, R. A. (1975) Effect of temperature on denitrification rate in soils. Proceeding of Soil Science Society of America 39, 867-870.

Tanaka, A., Kawana, K. and Yamaguchi, J. (1966) Photosynthesis, respiration, and plant type of the tropical rice plant. Technical Bulletin 7, 1-46.

Tanaka, A., Navasero, S. A., Garcia, C. V., Parao, F. T. and Ramirez, E. (1964) Growth habit of the rice plant in the tropics and its effect on nitrogen response. Technical Bulletin 3, 3-77.

Turner, F. T. (1979) Soil nitrification retardation by rice pesticides. Soil Science Society of America Journal 43, 955-957. 
Van Keulen, H. V. (1978) Simulation of influence of climatic factors on rice production. In Climatic Change and Food Production, ed. K. Takahashi and M. M. Yoshino, pp. 345-358, University of Tokyo Press, Tokyo.

Von Foerster, H. (1959) Some remarks on changing populations. In The Kinetics of Cellular Proliferation, ed. F. Stohlman, pp. 382-407. Grune and Stratton, New York.

Willers, J. L., Wagner, T. L., Sequira, R. A., Theseira, G. W. and Boykin, D. L. (1995) Analysis of deterministic simulation models using methods applicable to two-way treatment structures without replication. Agronomy Journal 87, 478492.

Wilson, L. T. and Gutierrez, A. P. (1980) Fruit predation submodel: Heliothis larvae feeding upon cotton fruiting structures. Hilgardia 48(2), 24-36.

Wilson, L. T. and Waite, G. K. (1982) Feeding pattern of Australian Heliothis on cotton. Environmental Entomology 11, 297-230.

Wilson, L. T., Gutierrez, A. P., Tennyson, R. and Zalom, F. G. (1987a) A physiological based model for processing tomatoes: crop and pest management. Acta Horticulturae 200, 125-132.

Wilson, L. T., Plant, R. E., Kerby, T. A., Zelinski, L. and Goodell, P. B. (19873). Transition from a strategic to a tactical crop and pest management model: use as an economic decision aid. In 1987 Proceedings Beltwide Cotton Production Research Conferences, pp. 207-213. Dallas, TX.

Wilson, L. T., Wu., G., Samonte, O.P. B. and Makela, M. E. (1996) Use of physiological modeling in quantifying the impact of weather on the 1995 late season yield decline. In Proceedings 26th Rice Technical Working Group, p. 134. Texas Agricultural Experiment Station, College Station, TX.

Wu, G. (1996) Biological systems approach to analyzing population dynamics of rice and its response to major physical and biotic variables. Ph.D. dissertation, Texas A\&M University, College Station, TX.

Wu, G. W. and Wilson, L. T. (1997) Analysis of the growth and yield response of rice to rice water weevil injury. Environmental Entomology (in press).

Yoshida, S. (1981) Fundamentals of Rice Crop Science. IRRI, Los Baiios.

Youngdahl, L. J., Pacheco, R., Street, J. J. and Vlek, P. L. G. (1982) The kinetics of ammonium and nitrate uptake by young rice plants. Plant and Soil 69, 225-232.

Zar, J. H. (1984) Biostatistical Analysis. Prentice-Hall, Englewood Cliffs, NJ.

Zhang, J. and Chen, C. G. (1990) Simulation of the dynamics of growth process and yield of rice population. Acta Ecologica Sinica 4, 311-316. 